\title{
AVALIAÇÃO DO PADRÃO DE VISITAÇÃO DE Apis mellifera EM TRÊS CULTIVARES DE MELOEIRO, EM PETROLINA-PE, BRASIL ${ }^{1}$
}

\author{
LÚCIA HELENA PIEDADE KIILL²; MÁRCIA DE SOUSA COELHO ${ }^{3}$; \\ KÁTIA MARIA DE MEDEIROS SIQUEIRA ${ }^{4}$; NIVALDO DUARTE COSTA ${ }^{5}$
}

RESUMO - Para o cultivo do meloeiro, a presença de abelhas no período de florescimento é fundamental para garantir a polinização e incrementar a produção de frutos. Nesse sentido, o presente trabalho teve por finalidade verificar se há diferenças no comportamento de visitas e no recurso floral forrageado por Apis mellifera, em três cultivares de meloeiro. O trabalho foi desenvolvido no Campo Experimental da Embrapa Semiárido, em Petrolina-PE, com as cultivares do tipo amarelo (BRS Araguaia), pele-de-sapo (P-33) e cantaloupe (CAN-4), com observações da biologia floral, morfologia e comportamento de A. mellifera no período das $05 \mathrm{~h}$ às $18 \mathrm{~h}$. O pico de visitação foi diferente, ocorrendo das $11 \mathrm{~h}$ às $12 \mathrm{~h} ; 10 \mathrm{~h}$ às $11 \mathrm{~h}$ e das $15 \mathrm{~h}$ às $16 \mathrm{~h}$ para o tipo amarelo, cantaloupe e pele-de-sapo, respectivamente. Quanto ao recurso floral forrageado, a coleta de néctar foi constante ao longo do dia, enquanto a de pólen ocorreu principalmente no período da manhã. Quanto ao tipo floral, as flores hermafroditas receberam, de modo geral, mais visitas na cultivar do tipo amarelo e pele-de-sapo, sendo o inverso registrado para a do tipo cantaloupe. O maior número de visitas registrado nesse tipo floral pode ser atribuído às diferenças morfológicas, uma vez que suas flores são maiores e, portanto, poderiam ser mais atrativas.

Termos para indexação: Cucumis melo L., BRS Araguaia, Pele-de-sapo, Cantaloupe

\section{ASSESSMENT OF VISITATION PATTERN OF Apis mellifera IN THREE TYPES OF MELON IN PETROLINA, PERNAMBUCO, BRAZIL}

\begin{abstract}
For the cultivation of melons, the presence of bees in the flowering period is critical to ensure pollination and increase fruit production. In this sense, this paper aims to verify whether there are differences in behavior and in the floral visits by Apis mellifera foraged in three types of melon. The study was conducted at the Experimental Field of Embrapa Semiárido, Petrolina, PE, with yellow-type cultivars (Araguaia BRS), piel de sapo melon (P-33) and cantaloupe (CAN-4), with observations of floral biology, morphology and behavior of $A$. mellifera in the period from 5:00 a.m. to 8:00p.m. The visitation's peak was different, occurring from 11:00 to 12:00a.m., 10:00 to 11:00a.m. and 03:00 to 04:00p.m. for the yellow kind, cantaloupe and piel de sapo, respectively. As for the floral foraging, collecting nectar was constant throughout the day, while pollen occurred mainly in the morning. Regarding the type floral, hermaphrodite flowers were, in general, more visits in the cultivar type and piel de sapo, the inverse of the type registered for the cantaloupe. The greatest number of visits recorded in this floral type can be attributed to morphological differences, since its flowers are larger and therefore could be more attractive.
\end{abstract}

Index terms: Cucumis melo L., BRS Araguaia, Pele de sapo, Cantaloupe

\footnotetext{
${ }^{1}$ Trabalho Sinfruit 128 - Simpósio Internacional de Fruticultura - Avanços na Fruticultura (17 a 21 Outubro)

${ }^{2}$ Bióloga, Doutorado em Biologia Vegetal, pesquisadora da Embrapa Semiárido; BR 428, Km 152, C.P. 23, zona rural, 56.302-970, Petrolina-PE. E-mail: kiill@cpatsa.embrapa.br

${ }^{3}$ Bolsista DTI/CNPq, Embrapa Semiárido, Petrolina-PE

${ }^{4}$ Medica Veterinária, Doutorado em Zoologia, profa. Da Universidade Estadual da Bahia, Juazeiro-BA.E-mail: katiaunb@yahoo.com.br

${ }^{5}$ Eng. Agrônomo, Mestre em Fitotecnia, pesquisador da Embrapa Semiárido, Petrolina-PE. E-mail: ndcosta@cpatsa.embrapa.br
} 


\section{INTRODUÇ̃̃O}

O melão é a oitava fruta produzida e ocupa a terceira colocação entre as principais frutas frescas exportadas pelo Brasil (AGRIANUAL, 2011). De acordo com Araújo-Neto et al. (2003), a cultura do melão assume importância expressiva nos Estados da Região Nordeste, tanto pela posição geográfica estratégica como pelas condições edafoclimáticas que favorem a interação genótipo $\mathrm{x}$ ambiente, proporcionando o desenvolvimento de frutos com qualidade para atender as exigências dos países importadores.

Os Estados do Rio Grande do Norte, Ceará, Paraíba, Pernambuco e Bahia concentram cerca de $90 \%$ da área total plantada no Brasil (AGRIANUAL, 2011). Apesar do excelente desempenho da cultura na região, ainda faltam cultivares e/ou híbridos adaptados à região em suas diversas épocas de plantio e que produzem frutos de qualidade para os comércios interno e externo.

Além disso, a produção de melão hoje depende da colocação de colônias de abelha melífera (Apis mellifera L.) nos plantios para assegurar a produtividade e a qualidade dos frutos, na maioria das áreas exploradas (FREITAS, 1998). As áreas cultivadas, normalmente, são carentes da presença de agentes polinizadores em quantidade e distribuição ideais, para assegurar bons índices de produtividade, ocorrendo o mesmo com o cultivo do meloeiro. Assim, os baixos índices de polinização nos plantios de melão podem contribuir para limitar a expressão de produção do material cultivado, tanto na produtividade quanto na qualidade dos frutos.

Dessa forma, o presente trabalho teve por objetivo comparar o padrão de visita de Apis mellifera em híbridos de meloeiro do tipo amarelo, pele de sapo e cantaloupe para verificar se há diferenças no comportamento e no recurso floral forrageado.

\section{MATERIAL E MÉTODOS}

O estudo foi realizado no Campo Experimental de Bebedouro, pertencente a Embrapa Semiárido, em Petrolina-PE (latitude $09^{\circ} 09^{\prime}$ S e longitude $40^{\circ} 22^{\prime} \mathrm{W}$ e altitude de $350 \mathrm{~m}$ ) no período de agosto à outubro de 2010. Para o experimento foram utilizados híbridos do tipo amarelo (BRS Araguaia), pele de sapo (PS-33/Procedência-CNPH) e cantaloupe (CAN-4/Procedência-CNPH).

O experimento constou de área total de $48 \mathrm{~m}^{2}$, divido em parcelas com espaçamento de $2,0 \mathrm{~m}$ entre fileiras e $0,40 \mathrm{~m}$ entre plantas. O plantio foi feito em datas diferentes visando sincronizar o período de colheita. Para o melão tipo amarelo, foi utilizado uma parcela de $20 \mathrm{~m}^{2}$, com 25 plantas, com plantio em 16 de agosto. Para o tipo pele de sapo e cantaloupe foram utilizadas parcelas de $12 \mathrm{~m}^{2}$ com 15 plantas por parcela, com plantio realizado em 10 e 23 de agosto, respectivamente.

Para o preparo do solo foi feita uma aração a $30 \mathrm{~cm}$ de profundidade, seguida de duas gradagem e sulcamento no espaçamento de $2,0 \mathrm{~m}$. O plantio das sementes foi feito em bandejas de isopor, com substrato para hortaliças, sendo colocado uma semente por célula. O transplantio para o local definitivo foi feito com 10 dias após a semeadura. A irrigação foi feita diariamente por gotejamento e a adubação de fundação foi feita de acordo com os resultados da análise do solo.

Para as observações da biologia floral, foram marcadas 20, 10 e oito flores para o tipo amarelo (BRS Araguaia), pele de sapo (PS-33) e cantaloupe (CAN-4), respectivamente. Essas foram acompanhadas ao longo do tempo de vida para verificar os horários de antese e senescência floral. Para a morfologia floral, observações complementares foram feitas em flores masculinas ( $\mathrm{n}=30,10$ para cada tipo) e hermafroditas ( $\mathrm{n}=14$, sendo 10 para BRS Araguaia; 03 para PS-33 e 01 para CAN-4). Nessas flores foram avaliados o diâmetro da corola, do cálice e a altura da flor, utilizando-se paquímetro digital.

Para o registro dos visitantes florais, observações simultâneas foram feitas em flores em pré-antese, nos dois tipos florais, nos três tipos de meloeiro. A freqüência e o comportamento dos visitantes foram observados no período de $05: 00 \mathrm{~h}$ às 18:00h, em quatro dias não consecutivos, totalizando 52 horas de esforço amostral. A presença dos visitantes foi contabilizada e anotada em planilhas, calculando-se o número médio de visitas por horário $(\mathrm{x}=\mathrm{n} / 4)$.

Para avaliar a produtividade das variedades, três frutos por tratamento foram selecionados ao acaso na parcela. Esses foram pesados, com auxílio de balança digital, e avaliados quanto aos sólidos solúveis totais ( ${ }^{\circ}$ brix), com auxilio de refratômetro digital Atago (0-32\%).

\section{RESULTADOS E DISCUSSÃO}

As observações da antese floral mostraram que não foram registradas diferenças em os três tipos de meloeiro, sendo o horário de abertura das flores masculinas e hermafroditas registrado por volta das $05 \mathrm{~h} 00$, podendo estender-se até $05 \mathrm{~h} 30$. Esses resultados concordam com os registros feitos por Abreu et al., (2008), que encontram flores de híbridos do tipo amarelo abrindo a partir de $5 \mathrm{~h} 20 \mathrm{~min}$., com uma 
amplitude de 5:00h a 5:50h.

Quanto à morfologia floral, verificou-se que as flores hermafroditas apresentaram dimensões maiores que as masculinas nos três parâmetros avaliados, sendo as maiores diferenças registradas para a altura da flor (Tabela 1). Analisando as flores masculinas, verificou-se que o tipo cantaloupe (CAN-4/Procedência-CNPH) apresentou flores maiores e mais altas, seguido pelo tipo amarelo (BRS Araguaia) e pele de sapo (PS-33/Procedência-CNPH). Já a comparação das flores hermafroditas mostrou que o tipo pele sapo (PS-33/Procedência-CNPH) apresentou flores maiores para os parâmetros diâmetro da corola e altura da flor. Dessa forma, as flores hermafroditas, por apresentarem dimensões maiores, poderiam ser mais atrativas à visitação do que as masculinas, tornando-as mais visíveis e com superfície maior que facilitaria o pouso da abelha.

Nas flores selecionadas para as observações dos visitantes florais foram registradas somente visitas de Apis mellifera, porém na área experimental observou-se Trigona spinipes visitando outras flores do tipo cantaloupe (CAN-4/Procedência-CNPH), coletando néctar. Com relação ao número médio total de visitas, registrou-se $170,1 \pm 9,05 ; 149,3 \pm 9,77$ e $95,7 \pm 6,23$ visitas no tipo cantaloupe, amarelo e pele de sapo, respectivamente. Na Figura 1 é apresentado o número médio de visitas por horário e mostra que no período de 05 h00 às 07 h00, o padrão de visitação foi baixo ou inexistente, sendo que esta mesma é observada no final da tarde (16h00 às 18h00).

Com relação ao pico de visitação, diferenças foram registradas nos três tipos de meloeiro estudados (Figura 1). No amarelo (BRS Araguaia), o padrão de visitação foi ascendente até o final da manhã, com pico de visitação registrado para o intervalo de $11 \mathrm{~h} 00$ às $12 \mathrm{~h} 00$. No período vespertino, verificou-se que o número de visitas diminuiu drasticamente, não havendo registros após às $17 \mathrm{~h} 00$. Para o cantaloupe (CAN-4), também foi registrado um padrão ascendente de visitação ao longo da manhã, porém o pico de visitação foi de $10 \mathrm{~h} 00$ às $11 \mathrm{~h} 00$. No período vespertino, o maior número de visitas foi observado no intervalo de $13 \mathrm{~h} 00$ às $14 \mathrm{~h} 00$, com cerca de 25 visitas de $A$. mellifera. No pele de sapo, as visitas no período matutino foram registradas a partir das $07 \mathrm{~h} 00 \mathrm{e}$, de modo geral, foram inferiores as observadas para os outros dois tipos. No período vespertino, houve um aumento do padrão de visitação a partir das $14 \mathrm{~h} 00$, com pico registrado para o intervalo das $15 \mathrm{~h} 00$ as $16 \mathrm{~h} 00$, quando foram registradas cerca de 18 visitas de A. mellifera.

Reyes-Carrillo e Cano-Ríos (2004) encontram padrão similar em observações feitas no México, com forrageamento registrado a partir das $08 \mathrm{~h} 00$ e o pico de visitação entre 11 h00 e 13 h00. Porém, Holanda Neto et al. (2000a e b, citado por Souza, 2008) comentam que, as flores do meloeiro são atrativas para Apis mellifera durante as primeiras horas da manhã, e que a atratividade pode variar de acordo com a cultivar utilizada. As diferenças encontradas com relação ao pico de visitação poderiam estar relacionadas às condições climáticas e a época do ano em que as observações foram feitas, que poderiam ter influenciado tanto o comportamento dos visitantes como a biologia floral.

Avaliando o padrão de visitação por recurso forrageado, verificou-se que no meloeiro do tipo amarelo (BRS Araguaia) as visitas de A. mellifera para coleta de pólen foram registradas principalmente no período da manhã, com pico registrado no intervalo de $08 \mathrm{~h} 00$ às $09 \mathrm{~h} 00$ (Figura 2a). Quanto ao néctar, o padrão de visitas foi ascendente até o final da manhã, apresentando queda ao longo da tarde. O pico de visita para esse recurso foi registrado para o intervalo de $11 \mathrm{~h} 00$ às $12 \mathrm{~h} 00$, coincidindo com o horário de maior visitação (Figura 1).

No meloeiro do tipo cantaloupe (CAN-4), as visitas de pólen foram registradas somente no período da manhã, enquanto as coletas de néctar foram registradas ao longo do dia, com pico nos intervalos de $10 \mathrm{~h} 00$ às $11 \mathrm{~h} 00 \mathrm{e}$ de $13 \mathrm{~h} 00$ às $14 \mathrm{~h} 00$, com cerca de 25 visitas em cada horário (Figura 2b). Para o meloeiro do tipo pele de sapo (PS-33), a coleta de pólen foi registrada no periodo de $07 \mathrm{~h} 00$ às $15 \mathrm{~h} 00$, com pico registrado no intervalo de $10 \mathrm{~h} 00$ às $11 \mathrm{~h} 00$. Já a coleta de néctar foi irregular ao longo do dia, com pico de visita registrado para o intervalo de $15 \mathrm{~h} 00$ às 16h00 (Figura 2c).

Comparando as Figuras 1 e 2, verificou-se que nos horários de maior visitação das flores do meloeiro dos três tipos, $A$. mellifera forrageia néctar. Esse fato pode estar relacionado a produção constante desse recurso pela flor, atraindo as abelhas ao longo do dia. Já a coleta de pólen se concentra no periodo da manhã, quando esse recurso é mais abundante, concordando com Holanda et al. (2000a e b). Comportamento semelhante foi registrado por Siqueira et al. (2008) na cultura da mangueira na região do Vale do São Francisco.

Com relação ao padrão de visitação por tipo floral, diferenças também foram observadas entre os três tipos (Figura 3). Nas flores do meloeiro do tipo amarelo (BRS Araguaia) e pele de sapo (PS-33), verificou-se que, de modo geral, as flores hermafroditas apresentarm número de visita igual ou superior as masculinas (Figura 3a e b). Somente nos intervalos de $06 \mathrm{~h} 00$ às $07 \mathrm{~h} 00$ e de $16 \mathrm{~h} 00$ às $17 \mathrm{~h} 00$, para o tipo 
amarelo, o inverso foi registro. Já no tipo Cantaloupe (CAN-4), as flores masculinas foram mais visitadas que as femininas no periodo de $06 \mathrm{~h} 00$ às $14 \mathrm{~h} 00$, sendo o inverso registrado no final da tarde. A maior visitação registrada para as flores perfeitas pode ser atribuido ao fato dessas apresentaram dimensões maiores, tornando-as mais atrativas, como discutido anteriormente.

Os dados de produtividade ( $\mathrm{t} / \mathrm{ha}$ ), peso médio do fruto $(\mathrm{Kg})$ e concentração de sólidos solúveis totais ( ${ }^{\circ}$ brix) dos três tipos estão na Tabela 2 e mostram que o tipo pele de sapo (PS-33) apresentou maior rendimento e peso médio dos frutos. No entanto, para a avaliação do ${ }^{\circ}$ brix, o tipo amarelo apresentou maior concentração de sólidos solúveis totais. As diferenças aqui encontradas podem estar relacionadas com as características genéticas de cada variedade, embora a visitação possa também ter influenciado.

TABELA 1. Características morfológicas avaliadas nas flores masculinas $(\overbrace{}^{\Uparrow})$ e hermafrodit $(\overbrace{}^{\Uparrow}+)$ de três tipos de meloeiro, em Petrolina-PE.

\begin{tabular}{|c|c|c|c|c|c|c|}
\hline \multirow[t]{2}{*}{$\begin{array}{l}\text { Morfologia } \\
\quad(\mathrm{cm})\end{array}$} & \multicolumn{2}{|c|}{$\begin{array}{c}\text { Amarelo } \\
\text { (BRS Araguaia ) }\end{array}$} & \multicolumn{2}{|c|}{$\begin{array}{c}\text { Pele de sapo } \\
\text { (PS-33/ P.-CNPH) }\end{array}$} & \multicolumn{2}{|c|}{$\begin{array}{c}\text { Cantaloupe } \\
\text { (CAN-4/ P.-CNPH) }\end{array}$} \\
\hline & $\hat{0}$ & 수우 & $\hat{0}$ & స우 & o & 웅 \\
\hline$\varnothing$ da corola & $\mathbf{3 1 , 0} \pm 2,81$ & $\mathbf{3 6 , 2} \pm 2,40$ & $\mathbf{3 0 , 3 5} \pm 3,78$ & $\mathbf{3 8 , 1 9} \pm 3,36$ & $\mathbf{3 6 , 4} ? \pm 3,55$ & 37,45 \\
\hline$\varnothing$ do cálice & $\mathbf{3 , 9 7} \pm 0,64$ & $\mathbf{8 , 0 ?} \pm 0,61$ & $\mathbf{3 , 8 1} \pm 0,64$ & $\mathbf{6 , 6 4} \pm 0,41$ & $\mathbf{3 , 9 ? ?} \pm 0,76$ & 6,52 \\
\hline Altura da flor & $\mathbf{6 , 2 3} \pm 0,88$ & $\mathbf{1 8 , 7} \pm 0,87$ & $\mathbf{5 , 4 9} \pm 0,69$ & $\mathbf{2 1 , 1 4} \pm 0,6$ & $7,1 ? ? \pm 0,81$ & 16,85 \\
\hline
\end{tabular}
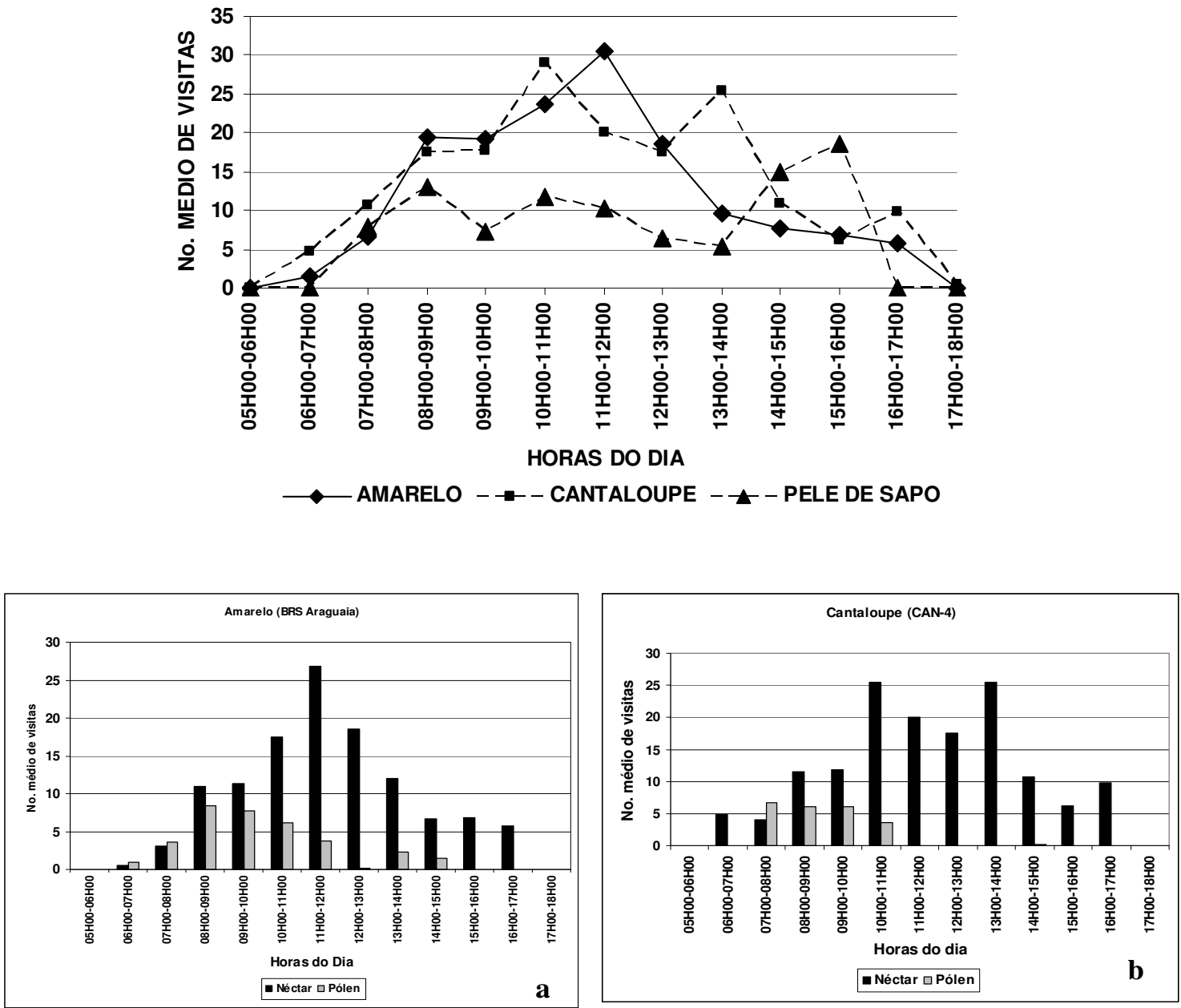

FIGURA 1 - Número médio de visitas, por horário, nos três tipos de meloeiro observados em Petrolina-PE. 


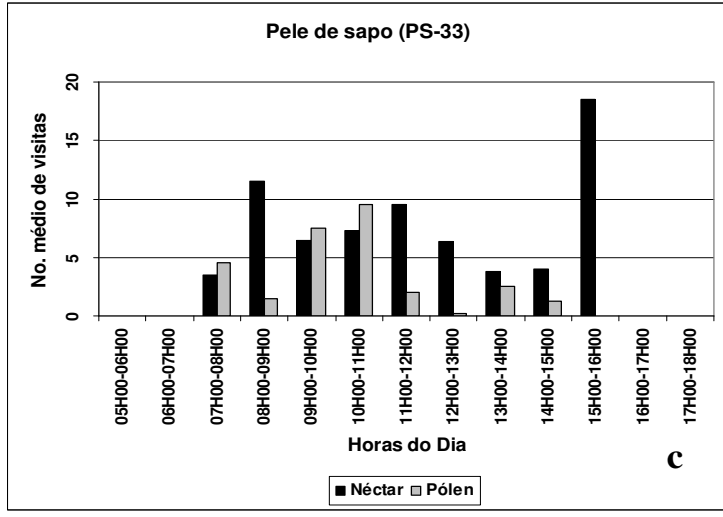

FIGURA 2 - Número médio de visitas, por recurso floral, por horário, nos três híbridos avaliados em Petrolina-PE
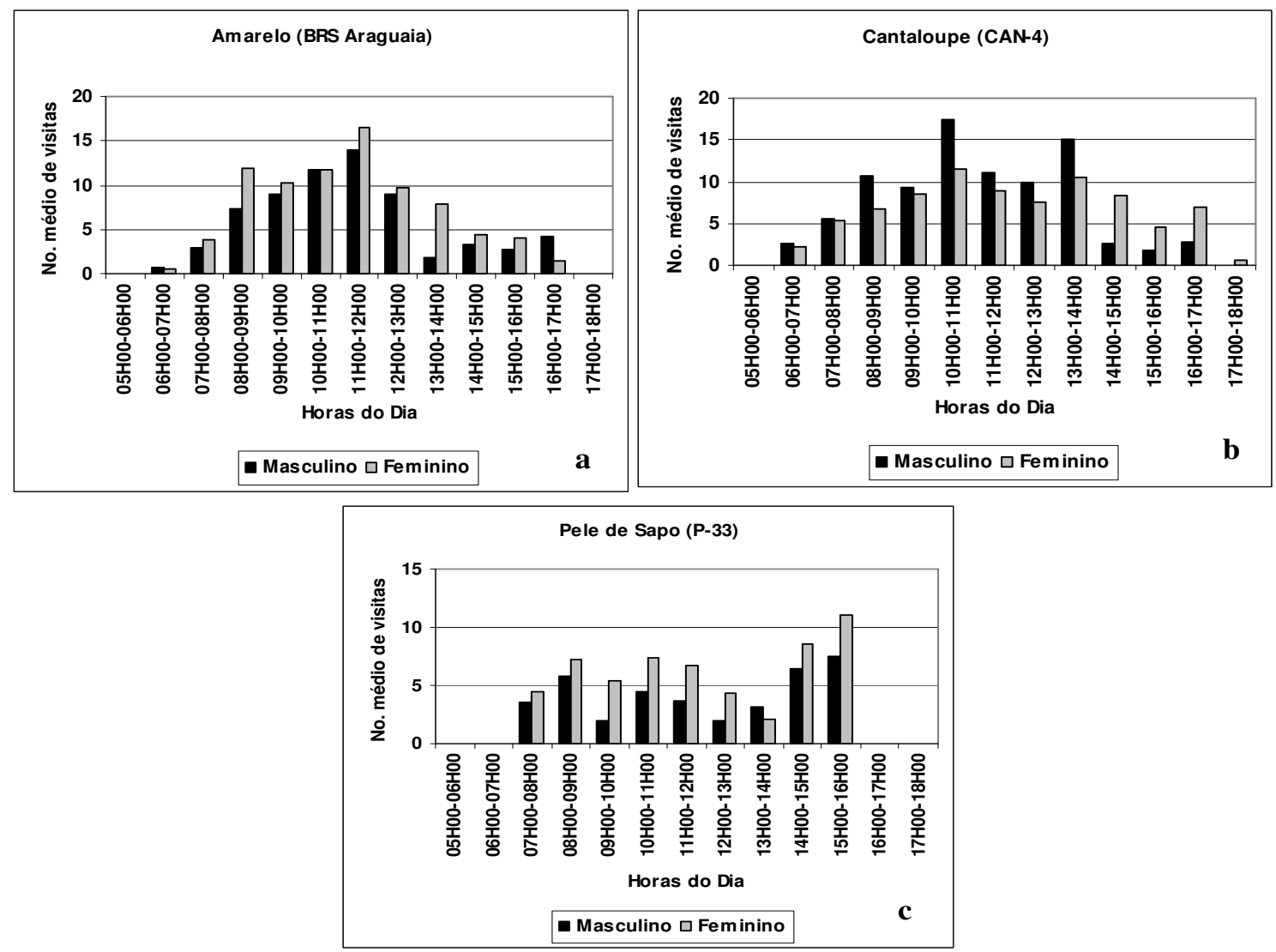

FIGURA 3 - Número médio de visitas por tipo floral, por horário, nos três híbridos avaliados em Petrolina-PE

TABELA 2 - Avaliação da produtividade, peso médio e brix ${ }^{\circ}$ dos frutos de três tipo de meloeiro em Petrolina-PE, 2010.

\begin{tabular}{lccc}
\hline \multicolumn{1}{c}{ Variedade } & $\begin{array}{c}\text { Produtividade } \\
\text { (t/ha) }\end{array}$ & $\begin{array}{c}\text { Peso médio do } \\
\text { fruto }(\mathbf{k g})\end{array}$ & 'Brix \\
\hline Amarelo (BRS Araguaia) & 37,50 & 1,56 & 13,53 \\
Pele de Sapo (PS-33) & 68,33 & 2,41 & 10,4 \\
Cantalupe (CAN-4) & 36,66 & 1,46 & 9,4 \\
\hline Média & $\mathbf{4 7 , 5 0}$ & $\mathbf{1 , 8 1}$ & $\mathbf{1 1 , 1 1}$ \\
\hline
\end{tabular}




\section{CONCLUSÕES}

Os resultados obtidos permitem dizer que a morfologia floral pode ter influenciado no padrão de visitação dos tipos florais do meloeiro e que esta pode variar de acordo com o cultivar. As visitas de Apis mellifera ocorreram ao longo do dia, com forrageamento de néctar constante e coleta de pólen principalmente no período da manhã.

\section{REFERÊNCIA}

ABREU, T.B.; NUNES, G.H.D E S. DANTAS, M.S.M.; COSTA FILHO, J.H.; COSTA, G.G.; ARAGÃO, F.A.S. Fenologia floral, viabilidade do grão de pólen e receptividade do estigma do meloeiro. Proceedings of the Interamerican Society for Tropical Horticulture. v.52, p. 43-46, 2008.

AGRIANUAL 2011: anuário da agricultura brasileira. São Paulo: FNP, Consultoria e Comércio, 2011. 355-358p.

ARAÚJO NETO, S.E.; GURGEL, F.L.; PEDROSA, J.F.; FERREIRA, R.L.F.; ARAÚJO, A.P. Produtividade e qualidade de genótipos de melão-amarelo em quatro ambientes. Revista Brasileira de Fruticultura, Jaboticabal, v. 25, n.1, p.104-107, 2003.
FREITAS, B.M. A importância relativa de Apis mellifera e outras espécies de abelhas na polinização de culturas agrícolas. In: ENCONTRO SOBRE ABELHAS, 3., 1998, Ribeirão Preto. Anais... Ribeirão Preto: USP, 1998. p. 10-20.

REYES-CARRILLO, M.C.J.L.; CANO-RÍOS, P. Honeybee distribution in the melon crop (Cucumis melo L) and their relationship with yield and quality. Tropical Beekeeping: Research and Development for Pollination and Conservation. Conference 22-25 February 2004 San José, Costa Rica.

SIQUEIRA, K. M. M. de; KIILL, L. H. P.; MARTINS, C. F.; LEMOS, I. B.; MONTEIRO, S. P.; FEITOZA, E. de A. Estudo comparativo da polinização de Mangifera indica L. em cultivo convencional e orgânico na região do Vale do Submédio do São Francisco. Revista Brasileira de Fruticultura, Jaboticabal, v. 30, n. 2, p. 303-310, 2008.

SOUSA, M. R. 2008. Polinização, Manejo de Colméias e Requerimentos do Meloeiro. p. 173-180. In: Sobrinho, R.B.; Guimarães, J.A.; Freitas, J.A.D.; Terao, D., eds. Produção Integrada de Melão. Embrapa Agroindústria Tropical, Banco do Nordeste do Brasil, Fortaleza, CE, Brasil. 